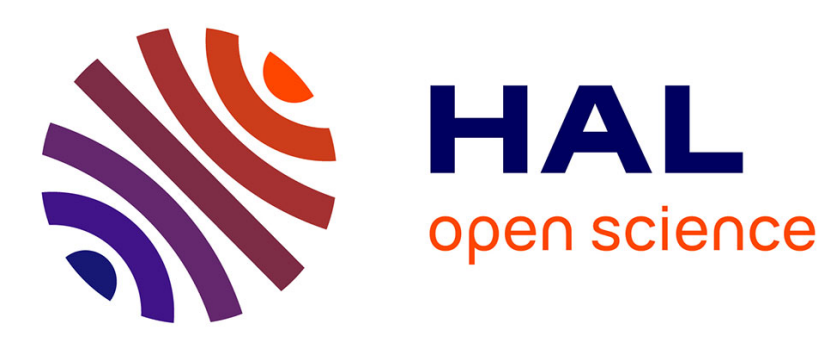

\title{
Decision Making for Sustainability: Review and Research Agenda
}

Mélanie Despeisse, Doroteya Vladimirova

\section{To cite this version:}

Mélanie Despeisse, Doroteya Vladimirova. Decision Making for Sustainability: Review and Research Agenda. IFIP International Conference on Advances in Production Management Systems (APMS), Sep 2014, Ajaccio, France. pp.146-153, 10.1007/978-3-662-44736-9_18 . hal-01387859

\section{HAL Id: hal-01387859 \\ https://hal.inria.fr/hal-01387859}

Submitted on 26 Oct 2016

HAL is a multi-disciplinary open access archive for the deposit and dissemination of scientific research documents, whether they are published or not. The documents may come from teaching and research institutions in France or abroad, or from public or private research centers.
L'archive ouverte pluridisciplinaire HAL, est destinée au dépôt et à la diffusion de documents scientifiques de niveau recherche, publiés ou non, émanant des établissements d'enseignement et de recherche français ou étrangers, des laboratoires publics ou privés.

\section{(c)(1)}

Distributed under a Creative Commons Attribution| 4.0 International License 


\title{
Decision Making for Sustainability: Review and Research Agenda
}

\author{
Mélanie Despeisse and Doroteya Vladimirova \\ Institute for Manufacturing, University of Cambridge, United Kingdom \\ $\{\mathrm{md} 621, \mathrm{dkv} 21\}$ @cam.ac.uk
}

\begin{abstract}
Manufacturers are failing to maximise the benefits from their own sustainability ambitions. Their decision-making methods and tools have not evolved to allow the non-financial dimensions of sustainability to be accounted for. Non-financial information is not systematically used in decision making as manufacturers do not yet know how to value qualitative benefits, opportunities and challenges. This paper reviews current challenges and the literature on decision-making for sustainability in manufacturing. The paper presents the need for a decision-making framework for sustainability and a research agenda for developing such a framework and delivering a supporting tool.
\end{abstract}

Keywords. Decision making for sustainability · Decision-making framework · Manufacturing strategy $\cdot$ Sustainable manufacturing

\section{Background and Problem Statement}

It is argued that manufacturers are missing sustainability improvement opportunities because it is not fully understood how decisions are made outside the traditional value system based on short-term financial value purely $[1,2]$. Manufacturers find it difficult to consider the medium- and long-term benefits for short-term decision-making for immediate actions, because they seek to monetize all the benefits in developing business cases focused on short-term profit. Additionally, even when there are financial benefits, sustainability activities are not necessarily undertaken [3].

Many manufacturers will already have a sustainability vision and strategy, yet they struggle to bring these into their day-to-day operational decisions [4,5]. Decisionmaking for sustainability is a growing research area as it has been recognised as a vital ingredient for success in modern businesses [6]. Decisions can be of different scale and frequency, e.g. new factory location vs. cleaning process sequence. Some successes have been achieved when the social and environmental dimensions have been monetized [7]. The traditional view of manufacturing companies' value capture regards the profit which is made when the goods and services are sold in relation to the cost of producing and delivering them, thus decisions are made purely based on financial profit (Fig. 1).

However the value created and potentially captured is not necessarily in the form of financial benefits. Industry is calling for more "useful" information for sustainability decision-making. Useful information can be defined as information that widens and specifies options to enable better results from implementation and to achieve 
desired objectives. The challenge manufacturers are facing is to monetize the benefits of long-term innovative sustainable solutions, such as organisational learning, knowledge exchange across disciplines and sectors, collaborative business models, closedloop and resilient industrial systems, or first mover advantage, even when useful information about these solutions are available.

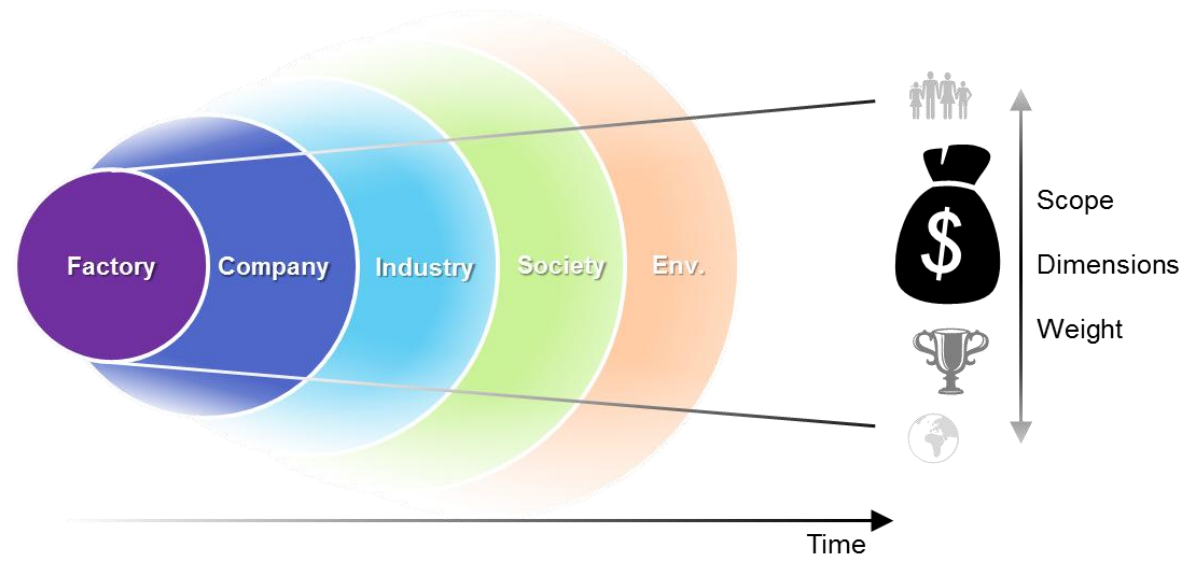

Fig. 1. Decision-making system for short-term financial benefits

In the context of today's increasing interconnectedness, complexity and multidimensionality of business operations and management, it is reasonable to assume that the benefits would become more interdependent and multifaceted as well. To reflect this multidimensionality, organisational decisions around sustainability have been depicted using the triple bottom line of people-planet-profit [8]; each dimension considered separately by experts and later on brought together. The difficulty is to combine these three dimensions for making final decisions [9]. As a result, decisionmaking is still dominated by a single index based on financial metrics and short-term thinking which do not adequately account for qualitative benefits. In other words, we have under-performing decision-making systems when it comes to industrial sustainability improvements.

There have been many efforts and initiatives to value ecosystem services [10], to link CSR and firm value [11], to develop a three-dimensional framework assessment [12] based on the triple bottom line [8]. There are also numerous tools like SWOT (Strengths-Weaknesses-Opportunities-Threats) [13], Environmental Impact Analysis (EIA), Strategic Environmental Analysis (SEA) and Cost-Benefit Analysis (CBA) [14] which are well-established and widely used for analysis, but the non-financial (yet useful) information is not systematically used in decision-making because we do not know how to value qualitative benefits, opportunities and challenges [15].

There is a gap in knowledge and a need in business practice to make the transition from the traditional decision-making thinking (Fig. 1) to a more holistic approach (Fig. 2) which (1) integrates the multiple dimensions of sustainability into business decision-making in a more balanced manner, (2) considers the benefits and implica- 
tions of today's actions on the long-term, and (3) expands the scope of decisionmaking to include the wider society and the natural environment.

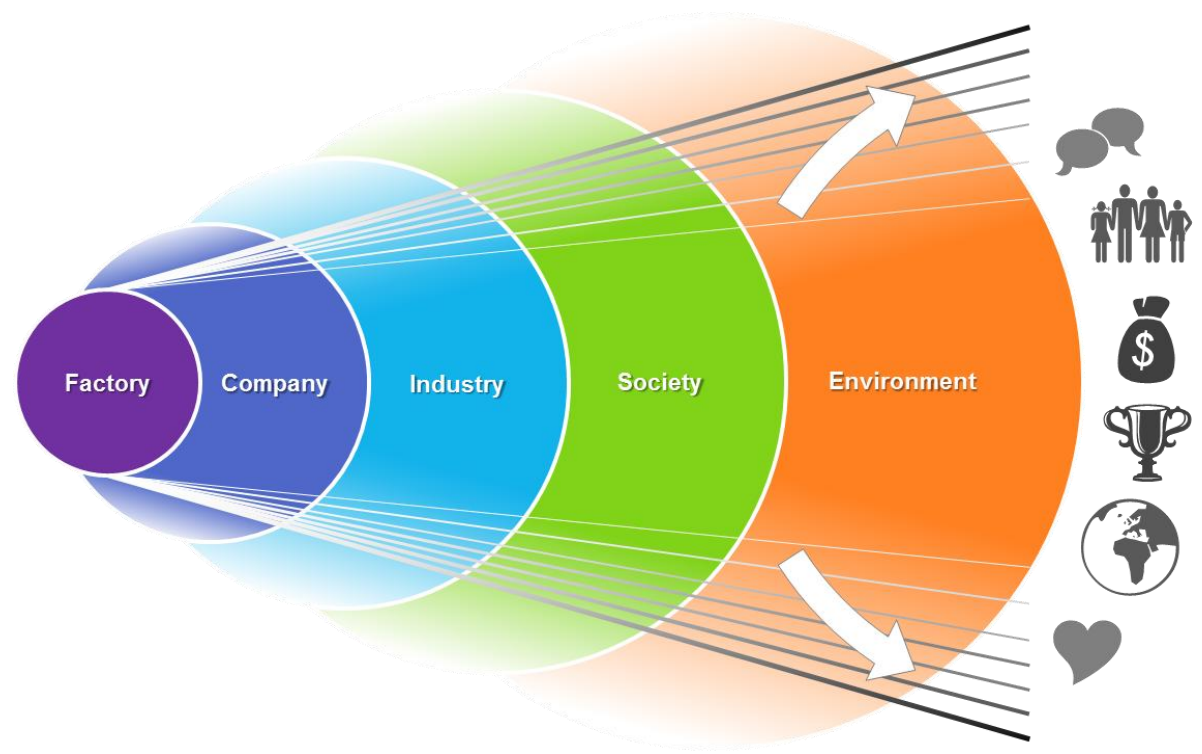

Fig. 2. Decision-making system for sustainability

This paper identifies and scopes the research problem around decision-making for sustainability, presents a set of research questions and proposes a research agenda to address the identified deficiencies.

\section{Research Questions and Deliverables}

We propose a research project that will help to develop the competencies manufacturers need as they move towards sustainability, for purposes of decision-making as well as value non-financial benefits, building resilience and organisational learning. The research aim is to better integrate sustainability into decision-making. This project will deliver a tool to support top-management in doing so: decision-making tool for sustainability (DMT4S).

We will address the following four research questions (RQ):

RQ1. What are the specific challenges when bringing sustainability into manufacturing decision-making?

RQ2. What dimensions should form part of sustainability decision-making in manufacturing?

RQ3. How to integrate these dimensions into sustainability decision-making tool?

RQ4. What happens when the DMT4S is used? 
The principal deliverables of this research are:

- A better understanding of sustainability decision-making in manufacturing.

- A theoretical framework that will identify a set of key themes and dimensions for sustainability decision-making. This will make a contribution to the scholarly literature on industrial sustainability strategy and decision-making.

- A decision-making tool for sustainability, or DMT4S. The tool will support the inclusion of sustainability considerations for better decision-making.

- Evidence of performance from multiple applications.

- A user guide to support companies in using the DMT4S. The tool will be professionally packaged to ensure user-friendliness.

- Workshops throughout the project as well as after its completion.

\section{Methodology and Project Plan}

The project will deliver a tool to support sustainability decision-making. The objectives are to better understand complex organisational problems in order to address the real-world problem of the integrating sustainability into decision-making, and to access superior opportunities and maximise performance, competitiveness and learning while accounting for the cost and risk involved.

Given the old dichotomy of theory and practice, a wider and deeper form of engagement between researchers and practitioners is needed in the co-production of knowledge [16]. Therefore we will adopt a strategy of engaged scholarship [17,18] as a means of knowledge production and collaborative inquiry between scholars and practitioners. Exploratory expert interviews will be conducted during the first year in phase 1. More intensive engagement will occur at key points such as phases 2 and 4 which will require extensive testing planning and analysis as well as exploitation planning. The core team will also meet bi-annually with the industrial collaborators for phases 2 and 3 . This will be done in workshops to be chaired by the principal investigators to gain industry guidance. This participative form of research will obtain the perspectives of key stakeholders (researchers, users and practitioners) to understand a problem of decision-making [18] and make research relevant to practitioners by bridging the gap between theory and practice [19]. Linkages to other relevant teams will be strongly maintained. We will share our findings at an early stage and update them regularly as empirical research proceeds to ensure that any assistance needed by other teams is provided.

The following sub-sections outline the work plan for the three research phases, deliverables and tasks allocation.

\subsection{Explore and plan}

This first phase aims at understanding current decision making for sustainability to address RQ1 and RQ2. We will review the literature and existing tools for decision- 
making in industrial sustainability at three levels to identify the strengths and weaknesses of decision-making at these different levels: best practice (eco-efficiency), technology solution (eco-factory), and business model. A vast body of management literature exists that provides a number of decision support tools but very little in support of sustainable industrial systems. There is a clear gap in knowledge about decision-making for sustainability. We will draw on the well-established stream literature on decision-making in organisations $[20,21]$ to strengthen the theoretical foundation of our work. We will identify concepts and constructs from this established literature and apply them to an emerging body of knowledge on decisionmaking for sustainability. In addition, we will conduct expert interviews with thought leaders in the area of industrial sustainability. Working closely with industry will allow us to strengthen and validate the theoretical framework and address an industry problem [18].

Tasks:

- Background review: Primarily review industrial sustainability and organisational decision-making literature. Review other relevant fields of research such as organisational learning, risk management, supply chain resilience, and corporate social responsibility.

- Existing tool review: Review existing tool in use by companies as well as tool recently developed for supporting sustainable business practices.

- Translate initial findings into specific questions and guidelines for structured interviews with industrial collaborators to learn from best practice.

- Theory building: Establish a theoretical framework for the decision-making tool.

\subsection{Develop and learn}

In this second phase, we will develop a prototype tool for sustainability decisionmaking, identify and overcome weaknesses of the proposed tool through targeted testing (fast prototyping) to address RQ2 and RQ3. Through the use of fast prototypes, we will test the framework and tool from early stages of development to continuously test and refine the tool. Each fast prototype will focus on specific elements of the tool to insure their validity. We will use lessons learnt from these prototype applications to develop and refine the final DMT4S.

Tasks:

- Define tool specifications based on the theoretical framework and interview results from phase 1 .

- Develop the initial tool and use targeted testing (fast prototypes).

- Continuously test and refine the framework and tool using data captured during phases 2 and 3 . 
- Use lessons learned from the fast prototype applications to inform the DMT4S development.

\subsection{Use and prove}

In this third phase, we will test the prototype tool and final DMT4S to deliver results and evidence of performance to address RQ3 and RQ4. We will first test the fast prototypes to validate various elements of the prototype tool before approaching industrial collaborators through our established network. Central to engaged scholarship is building relationships between academics and practitioners through the creation of joint forums, researcher/practitioner gatherings and focus groups that consider issues of concern to both academics and practitioners [22]. We will use workshops to test the usability of the tool and create a user guide. Finally we will package the tool (e.g. website, software development, user guide printing, etc.) to facilitate the dissemination of our findings through the use of the tool.

Tasks:

- Use fast prototype applications to review the validity of the framework.

- Use fast prototype applications to test the performance of the tool.

- Analyse tool use and synthesise users' feedback to refine the tool.

- Finalise the DMT4S and user guide based on lesson learnt from use.

- Assess the overall performance and quality of the tool.

- Package and distribute the DMT4S.

\section{Project Outcomes and Implications}

Globalisation of manufacturing has resulted in an increasing number of emerging economies competing for a limited pool of resources. In order to remain competitive, manufacturers will need to improve their resource efficiency and improve the resilience of their supply chain against disruptions. Although there is ample knowledge about these issues, manufacturers are still struggling to concretely address them and integrate them into their decision-making. Industry and the environment have long been opposed: industrial improvements for the environment are considered as a cost, although it is not necessarily the case [1].

Manufacturers are often reluctant to take action because they fear it will be at too high a cost in the short-term and result in uncertain generalised benefits in the distant future. To develop more sustainable industrial systems, industrialists and policy makers need to better understand and take decisions on how to respond to environmental, social and economic challenges and transform industrial behaviour accordingly leveraging appropriate investment and implementation of new tools and approaches. Important issues and opportunities around sustainable manufacturing can be addressed by improving decision-making. 
We propose a research project that will explore a concrete issue in the manufacturing industry: decision-making for the sustainability transition towards resource efficiency, circular economy, resilience, and organisational learning. The work will provide a better understanding of the multi-dimensionality of corporate decision-making for sustainability and advance the academic fields of industrial sustainability and organisational decision-making. It will also contribute to knowledge in the areas of corporate social responsibility, strategic planning, resilience, uncertainty and risk management. The tool developed will support the sustainability transformation of manufacturing companies in a novel manner and provide a contribution to academic literature, disseminated via journal papers and conference presentations.

This project fits with the need to strengthen the manufacturing sector in a forwardlooking and sustainable manner. A greater focus on long-term impact of decisionmaking will help firms increase resilience and reduce costs. For sustainability improvements to take place, constant efforts are needed in resource efficiency and innovation. Organisations making these efforts will be rewarded with strong performance improvements. This project will involve best practice leaders with high visibility aiming to encourage the rest of the manufacturing industry to follow their lead.

\section{References}

1. Porter ME, Kramer MR (2011). Creating Shared Value: How to reinvent capitalism - and unleash a wave of innovation and growth. Harvard Bus. Rev. 89(1/2): $62-77$.

2. Lavery G, Pennell N, Brown S, Evans S (2013). Next Manufacturing Revolution. Available at: http://www.nextmanufacturingrevolution.org/ [accessed 2407-2013]

3. Tsui A (2013). On Compassion in Scholarship: Why Should We Care? Acad. Manage. Rev. 38(2): 167-180.

4. Epstein MJ, Roy MJ (2001). Sustainability in action: Identifying and measuring the key performance drivers. Long Range Plann. 34(5): 585-604.

5. Lueneburger C, Goleman D (2010). The Change Leadership Sustainability Demands. MIT Sloan Manage. Rev. 51(4): 49-55.

6. Arvai J, Campbell-Arvai V, Steel P (2012). Decision-Making for Sustainability: A Systematic Review of the Body of Knowledge. Ontario: Network for Business Sustainability.

7. Turner RK, Paavola J, Cooper P, Farber S, Jessamy V, Georgiou S (2003). Valuing nature: lessons learned and future research direction. Ecol. Econ. 46(3): 493510 .

8. Elkington J (1997). Cannibals with Forks: The Triple Bottom Line of $21^{\text {st }}$ Century Business, Oxford: Capstone Publishing.

9. Gibson RB (2006). Beyond the Pillars: Sustainability Assessment as a Framework for Effective Integration of Social, Economic, and Ecological Considera- 
tions in Significant Decision Making. J. Environ. Asses. Policy Manage. 8(3): 259-280.

10. de Groot RS, Alkemade R, Braat L, Hein L, Willemen L (2010). Challenges in integrating the concept of ecosystem services and values in landscape planning, management and decision making. Ecol. Complex. 7(3): 260-272.

11. Edmans A (2012). The Link Between Job Satisfaction and Firm Value, with Implications for Corporate Social Responsibility. Acad. Manage. Perspect. 26(4): 1-19.

12. Hacking T. Guthrie P (2008). A framework for clarifying the meaning of Triple Bottom-Line, Integrated, and Sustainability Assessment. Environ. Impact. Asses. 28: 73-89.

13. Rowe AJ, Mason RO, Dickel KE, Mann RB, Mockler RJ (1994). Strategic Management: a methodological approach $\left(4^{\text {th }} \mathrm{ed}\right)$. Reading Mass: AddisonWesley.

14. Hundloe T, McDonald GT, Ware J, Wilks L (1990). Cost-benefit analysis and environmental impact assessment. Environ. Imp. Asses. Rev. 10(1-2): 55-68.

15. McNie EC (2007). Reconciling the supply of scientific information with user demands: an analysis of the problem and review of the literature. Environ. Sci. Policy 10(1): 17-38.

16. Pettigrew A (2001). Management research after modernism. Brit. J. Manage. 12: 61-70.

17. Van de Ven AH, Johnson PE (2006). Knowledge for theory and practice. Acad. Manage. Rev. 31(4): 802-821.

18. Van de Ven AH (2007). Engaged Scholarship: A Guide for Organisational and Social Research, New York: Oxford University Press.

19. Barge JK, Shockley-Zalabak P (2008). Engaged Scholarship and the Creation of Useful Organisational Knowledge. J. Appl. Commun. Res. 36(3): 251-265.

20. Weber M (1947). The Theory of Social and Economic Organization, Glencoe, Illinois: The Free Press.

21. Miller SJ, Hickson DJ, Wilson DC (1996). Decision-Making in Organizations. In: Clegg SR, Hardy C, Nord WR (eds). Handbook of Organizational Studies, London: Sage.

22. Bartunek JM (2007). Academic-practitioner collaboration need not require joint or relevant research: toward a relational scholarship of integration. Acad. Manage. J. 50(6): 1323-1333. 